\title{
Respostas hidrológicas em pequenas bacias na região semiárida em função do uso do solo
}

\author{
Joseilson O. Rodrigues', Eunice M. de Andrade', Luiz A. R. Mendonça ${ }^{2}$, \\ José C. de Araújo', Helba A. de Q. Palácio ${ }^{3}$ \& Efraim M. Araújo ${ }^{1}$
}

\begin{abstract}
RESUMO
Propôs-se, neste estudo, avaliar e comparar o comportamento hidrológico em pequenas bacias investigando a influência da ação antrópica sobre as respostas hidrológicas. O estudo foi conduzido em duas microbacias adjacentes e com distintos usos da terra, denominadas B1 e B2, no semiárido do nordeste do Brasil. Na microbacia B1 foi aplicado o manejo de raleamento eliminando-se as espécies vegetais com diâmetro inferior a $10 \mathrm{~cm}$; na segunda (B2) se manteve a cobertura vegetal original, a qual não é explorada há mais de 30 anos. Nesta investigação foram considerados 24 eventos chuva-deflúvio, correspondendo a toda estação chuvosa de 2009, cujos resultados revelaram que a prática de raleamento da caatinga apresentou modificações no escoamento mas apenas nos eventos inicias e que o rápido crescimento da vegetação herbácea reduziu o escoamento superficial direto na microbacia raleada, que apresentou valores de lâminas escoadas inferiores aos da microbacia preservada; verificou-se, contudo, que as descargas máximas na microbacia raleada foram superiores às da bacia preservada.
\end{abstract}

Palavras-chave: microbacias, escoamento superficial, raleamento, picos de descarga

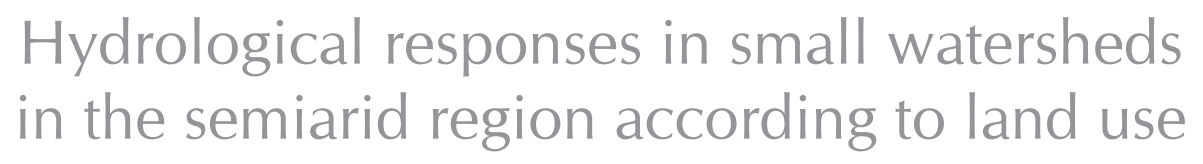

\begin{abstract}
The main goal of this study was to evaluate and to compare the hydrological behavior of small watersheds investigating the influence of the anthropogenic activities and the hydrologic responses due to these activities. The experimental area was composed of two small watersheds denominated B1 and B2. In watershed B1, a treatment (thinning) was applied, eliminating the species with diameters less than $10 \mathrm{~cm}$. The experimental watershed B2 was not submitted to any treatment maintaing the original vegetation. In this investigation a total of 24 rainfall-runoff events were considered, corresponding to the 2009 rainy season as a whole. The results revealed that the thinning of the caatinga generated modifications in the runoff only in the initial rainy season. The growing of herbaceous vegetation attenuated the water flow and reduced the runoff in B1, promoting small changes in response to the applied treatment. There were, however, higher peak discharges in watershed B1 compared with the preserved watershed.
\end{abstract}

Key words: watershed, runoff, thinning, peak discharge

DENA/UFC, Campus do Pici, Av. Mister Hull, s/n, Bloco 804, CEP 60455-970, Fortaleza, CE. Fone: (85) 3366-9762. E-mail: joseilson@cariri.ufc.br; eandrade@pq.cnpq.br; jcaraujo@ufc.br; efraimirrigacao@gmail.com

${ }^{2}$ Curso de Engenharia Civil/UFC, Campus do Cariri, Av. Tenente Raimundo Rocha, s/n, Cidade Universitária, CEP 63000-000, Juazeiro do Norte, CE. Fone: (88) 3572-7200. E-mail: larm@ufc.br

${ }^{3}$ IFCE, Campus Iguatu, Rodovia Iguatu, Alegre Km 05, s/n, C.P. 38, Vila Cajazeiras, CEP 63500-000, Iguatu, CE. Fone (88) 3582-1000. E-mail: helbaraujo23@yahoo.com.br 


\section{INTRODUÇÃO}

As regiões semiáridas são zonas de alta fragilidade, nas quais vivem aproximadamente $20 \%$ da população mundial (Gaiser et al., 2003). O manejo antrópico inadequado de pequenas bacias nesta região pode proporcionar sérios reflexos negativos, como alterações das respostas hidrológicas, erosão em áreas agrícolas e redução da capacidade hidráulica de reservatórios (Araújo et al., 2006). As alterações hidrossedimentológicas em microbacias são passíveis de ocorrência também em condições naturais porém os efeitos das modificações sobre a cobertura vegetal agravam os problemas acima mencionados podendo provocar alterações no padrão de infiltração, no balanço de água superficial e subterrâneo assim como produzir assoreamento (Srinivasan et al., 2003; Brito et al., 2008; Mamede, 2008; Medeiros et al., 2010). Apesar do desenvolvimento de alguns estudos conduzidos no semiárido sobre alterações hidrológicas em microbacias, mais pesquisas devem ser realizadas no sentido de gerar informações em microbacias de escoamento efêmero investigando, sobremaneira, a influência antrópica na alteração dos processos naturais (Srinivasan et al., 2003; Bartley et al., 2006; Mello et al., 2007; Garcia-Ruiz et al., 2008; Santos et al., 2010).Um dos desafios neste sentido é a dificuldade do monitoramento contínuo na geração de informações qualitativas e quantitativas consistentes em bacias de cursos efêmeros.

A lacuna existente no conhecimento sobre o impacto da ação antrópica na alteração das respostas hidrológicas no bioma Caatinga é incipiente ou inexistente. Contudo, sabe-se que neste bioma endêmico, encontrado no semiárido nordestino, é comum o desmatamento como resultado de extração de lenha e manejo agrícola adotado (Aguiar et al., 2006). Entretanto, os impactos hidrológicos oriundos dessas práticas não foram ainda totalmente mensurados. Neste contexto, surge a questão científica: modificações na cobertura vegetal como o raleamento da Caatinga, são suficientes para alterar, de forma significativa, a resposta hidrológica de microbacias hidrográficas? Sabe-se que em outros ecossistemas intervenções deste tipo têm sido constatadas com frequência (Kang et al., 2001; Iroumé et al., 2006; Thomaz, 2009), o que aumenta a relevância da pesquisa. Ante o exposto, surge a hipótese de que a retirada parcial da vegetação no bioma caatinga por ações antrópicas é capaz de alterar as respostas hidrológicas em bacias hidrológicas localizadas nessas áreas de alta fragilidade ambiental, seja reduzindo a disponibilidade hídrica pelo aumento do escoamento ou elevando os picos de descarga máxima.

Desta forma objetivou-se, com este estudo, avaliar e comparar o comportamento hidrológico em pequenas bacias com usos distintos da terra, tanto como gerar informações sobre os processos chuva-deflúvio em microbacias com escoamento efêmero no semiárido do Nordeste.

\section{MATERIAL E MÉTOdos}

A área de estudo localiza-se na Bacia do Alto Jaguaribe, município de Iguatu, na região Centro Sul do Ceará, entre as coordenadas geográficas $6^{\circ} 23^{\prime} 42^{\prime \prime}$ a $6^{\circ} 23^{\prime} 47^{\prime \prime} \mathrm{S}$ e $39^{\circ} 15^{\prime}$ 24 " a $39^{\circ} 15^{\prime} 29^{\prime \prime} \mathrm{W}$ (Figura 1).

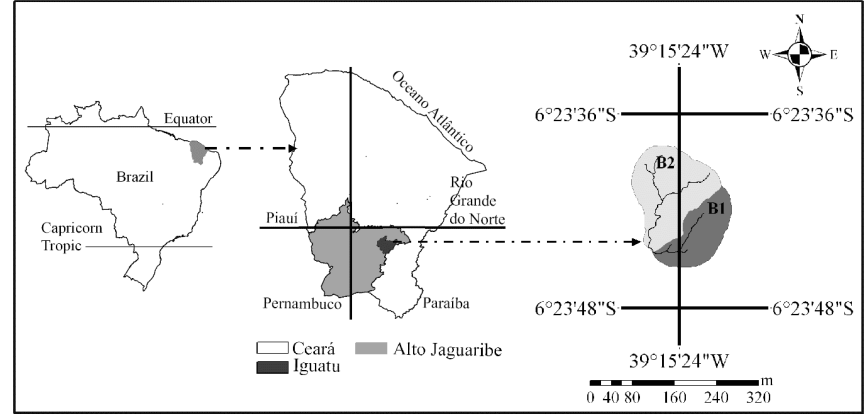

Figura 1. Localização das microbacias no estado do Ceará, Brasil

O bioma de desenvolvimento do trabalho é tipicamente de Caatinga, enquadrada mais especificamente como caatinga arbustiva-arbórea fechada, havendo predominância de plantas caducifólias, que perdem suas folhas entre o final das chuvas e o início da estação seca.

O clima da região é semiárido do tipo BSw'h', com chuvas máximas de outono e temperatura média mensal sempre superior a $18{ }^{\circ} \mathrm{C}$ (Andrade et al., 2007). A precipitação média histórica no município de Iguatu entre os anos de 1974 e 2008 foi de $970 \mathrm{~mm}$ anuais, como desvio padrão de $316 \mathrm{~mm} \mathrm{ano}^{-1}$, tendo valores mínimos e máximos de 433 e $2072 \mathrm{~mm}$ registrados em 1983 e 1985, respectivamente (FUNCEME, 2009).A região é caracterizada também por alta evaporação potencial (1988 $\mathrm{mm}$ ano $^{-1}$ ) com maiores valores durante os sete meses de menor precipitação (junho a dezembro). A geologia da região é formada de sedimentos mesomicroclásticos, que sofreram um processo de afundamento proporcionando a formação de solos com relevo plano a suave ondulado. A cobertura vegetal é composta principalmente de espécies vegetais herbáceas, como Hyptissauaviolens (L.) point (Bambural) e Hyptissp. (melosa) seguida, em menor proporção, de espécies vegetais de caráter arbustivo e arbóreo, como Aspidosperma pyrifolium Mart (Pereiro) (Alves, 2008). O solo das microbacias é Vertissolo Ebânico carbonático típico, com formação litológica das rochas sedimentares da Bacia do Iguatu e solos argilosos, com argila 2:1, do grupo montimorilonita.

Aárea experimental consiste de duas microbacias hidrográficas adjacentes com uso distinto da terra, denominadas B1 e B2 com dimensões de, respectivamente, 1,1 e 2,1 ha; as declividades médias dessas microbacias são de, respectivamente, 8,7 e 10,6\%, com cursos de drenagem de regime hidrológico efêmero.

O tempo de concentração (tc) foi estimado a partir do intervalo de tempo decorrido entre o fim da precipitação e o início da curva de recessão do hidrograma (Tucci, 2007) utilizando-se hidrogramas de 15 eventos chuva-deflúvio registrados no ano de 2009; as características morfométricas e edafoclimáticas das microbacias estão apresentadas na Tabela 1.

$\mathrm{Na}$ microbacia $\mathrm{B} 1$ a vegetação natural arbustiva com diâmetro inferior a $10 \mathrm{~cm}$ foi removida (raleada) para simular o efeito antrópico sobre a alteração das respostas hidrológicas em pequenas bacias hidrográficas; apesar disto, no local foi constatado o crescimento da vegetação herbácea (Figura 2A e B). A microbacia B2 foi mantida sem alterações na cobertura vegetal simulando a condição naturalmente encontrada em regiões semiáridas. 
Tabela 1. Características das microbacias experimentais B1 e B2

\begin{tabular}{|c|c|c|c|c|}
\hline \multirow{2}{*}{\multicolumn{2}{|c|}{ 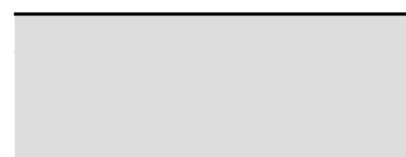 }} & \multicolumn{2}{|c|}{ Microbacias } & \multirow[b]{2}{*}{ Unidades } \\
\hline & & $\begin{array}{c}\text { B1 } \\
\text { Caatinga } \\
\text { raleada }\end{array}$ & $\begin{array}{c}\text { B2 } \\
\text { Caatinga } \\
\text { nativa }\end{array}$ & \\
\hline
\end{tabular}

\begin{tabular}{lrrr} 
Área da bacia & 1,10 & 2,10 & $(\mathrm{ha})$ \\
Comprimento do curso principal & 147,20 & 252,10 & $(\mathrm{~m})$ \\
Comprimento da bacia & 188,20 & 204,40 & $(\mathrm{~m})$ \\
Declividade da bacia & 8,70 & 10,60 & $(\%)$ \\
Tempo de concentração & 0,57 & 0,68 & $(\mathrm{~h})$ \\
Sinuosidade do curso principal & 1,20 & 1,40 & $(-)$ \\
Fator de forma & 0,32 & 0,49 & $(-)$ \\
Coeficiente de compacidade & 1,25 & 1,16 & $(-)$ \\
\hline \multicolumn{4}{c}{ Solo e cobertura vegetal } \\
Condutividade hidráulica & 0,10 & 0,20 & $\left(\mathrm{~mm} \mathrm{~h}^{-1}\right)$ \\
Saturada (K sat $_{\text {a }}$ (0-30 cm) & 43,00 & 45,00 & $(\%)$ \\
Areia & 46,00 & 45,10 & $(\%)$ \\
Silte & 11,00 & 10,00 & $(\%)$ \\
Argila & 2,00 & 2,60 & $(\%)$ \\
Matéria Orgânica & Franca & Franca & $(-)$ \\
Classe textural & 17 & 49 & $(\%)$ \\
Cobertura vegetal arbustiva & 100 & 70 & $(\%)$ \\
Cobertura vegetal herbácea & & & \\
\hline
\end{tabular}

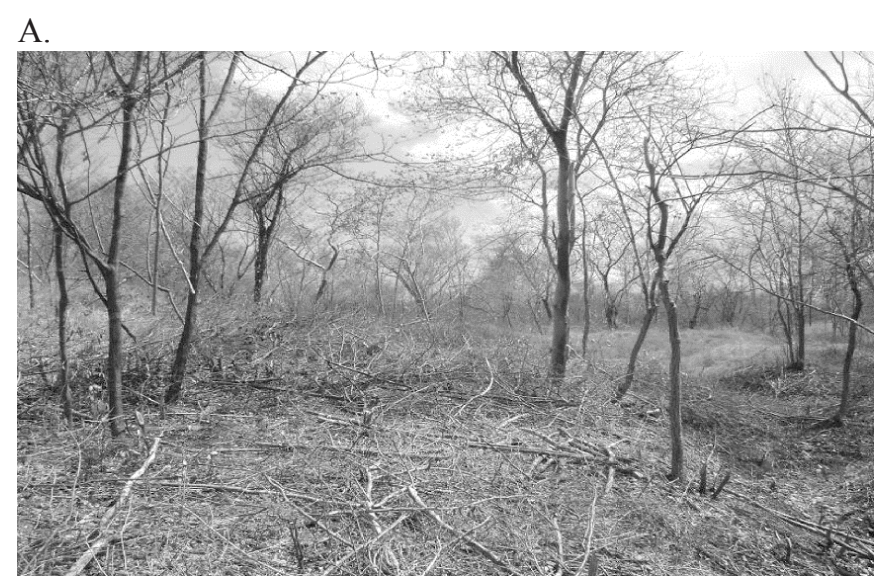

B.

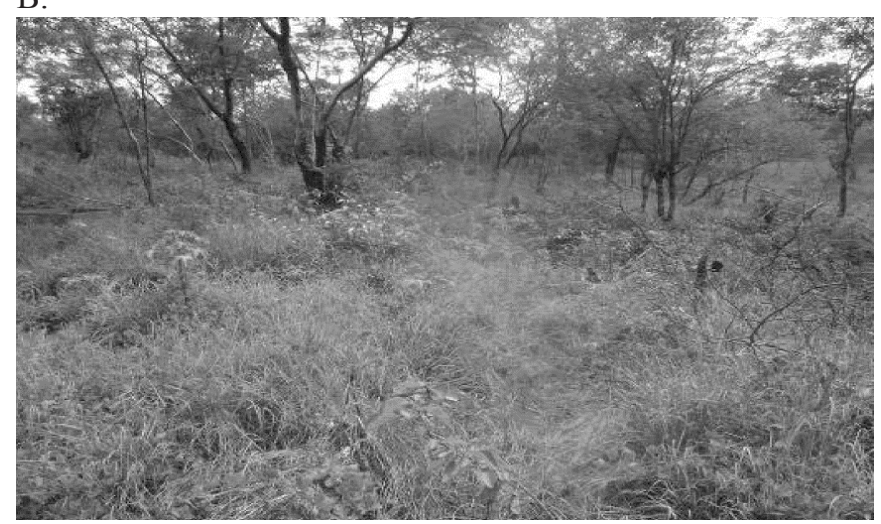

Figura 2. Raleamento na microbacia hidrográfica B1 (novembro 2008) (A); cobertura vegetal herbácea na microbacia B1 após o raleamento (fevereiro 2009) (B)

Os dados hidrológicos empregados nesta investigação foram referentes à estação chuvosa do ano de 2009 (janeiro a maio); as duas microbacias foram equipadas com calhas Parshall aparelhadas com linígrafos e pluviógrafos automáticos com resolução de $0,254 \mathrm{~mm}$ e a coleta de dados foi feita a cada 5 min. Os deflúvios superficiais monitorados nas calhas Parshall foram convertidos posteriormente em volume escoado.

Devido à sensibilidade mínima dos linígrafos, foram registradas apenas vazões superiores a $1,0 \mathrm{~L} \mathrm{~s}^{-1}$ na avaliação dos eventos individuais e consideraram-se como novo evento de deflúvio os registros após $12 \mathrm{~h}$ de inexistência de escoamento.

Nesta investigação realizou-se análise comparativa entre as microbacias contando-se principalmente com as lâminas escoadas, as intensidades máximas em 30 min $\left(\mathrm{I}_{30}\right)$ e as vazões específicas máximas $\left(\mathrm{Q}_{\text {esp }}\right)$ como parâmetros avaliados.

Correlacionaram-se, linearmente, as vazões específicas máximas com as intensidades máximas em 30 min $\left(\mathrm{I}_{30}\right)$ e também as vazões específicas com as precipitações acumuladas anteriormente a cada pico; referidas correlações foram empregadas para avaliar individualmente a interferência das variáveis intensidade $\left(\mathrm{I}_{30}\right)$ e acúmulo de água no solo, sobre a elevação das descargas máximas em cada uma das duas microbacias.

Para cada uma das correlações lineares foi realizada análise de variância com o propósito de verificar o modelo de melhor ajuste (Milton, 1992); as análises foram feitas utilizandose o aplicativo estatístico "Statistical Package for Social Sciences”(SPSS) versão 16.0.

\section{Resultados E Discussão}

$\mathrm{O}$ raleamento da microbacia $\mathrm{B} 1$ foi aplicado em novembro de 2008 e o primeiro evento com geração de escoamento foi observado no dia 30-01-09. Neste evento a lâmina escoada foi $132 \%$ superior em relação à microbacia preservada $\mathrm{B} 2$ (Figura 3). O evento do dia 02-02-09 não foi registrado em B2 devido às falhas nos sistema de aquisição e transmissão de dados dos equipamentos; já o evento do dia 04-02-09 também apresentou lâmina escoada superior em B1, sugerindo influência do tratamento na elevação do escoamento nos eventos iniciais.

Nos eventos subsequentes (a partir de 12-02-09 e 28-0209) observou-se uma inversão nas lâminas escoadas e nos percentuais de umidade do solo das duas microbacias para uma mesma altura pluviométrica. A microbacia raleada (B1) passou a apresentar maior umidade do solo e menor lâmina escoada, cujo comportamento identifica que o crescimento da vegetação herbácea pós-raleamento em B1 contribuiu para o aumento da umidade do solo aumentando a oportunidade de infiltração e reduzindo a lâmina escoada levando a uma condição de maior retenção de água do que a microbacia preservada. Resultados encontrados por Garcia-Ruiz et al. (2008) em microbacias no semiárido da Espanha ratificam os encontrados nesta pesquisa.

A recuperação da vegetação rasteira iniciou-se após os primeiros eventos de chuva e aumentou progressivamente até o final da estação chuvosa (Figura 2B). Uma vez estabelecida a cobertura vegetal, juntamente com restos culturais deixados sobre o solo, passam a atuar como pontos de dissipação de energia promovendo, assim, maior oportunidade de infiltração favorecendo a retenção de água no sistema e modificando o padrão das respostas hidrológicas. Srinivasan et al. (2003) verificaram maiores lâminas escoadas sobre microbacias 


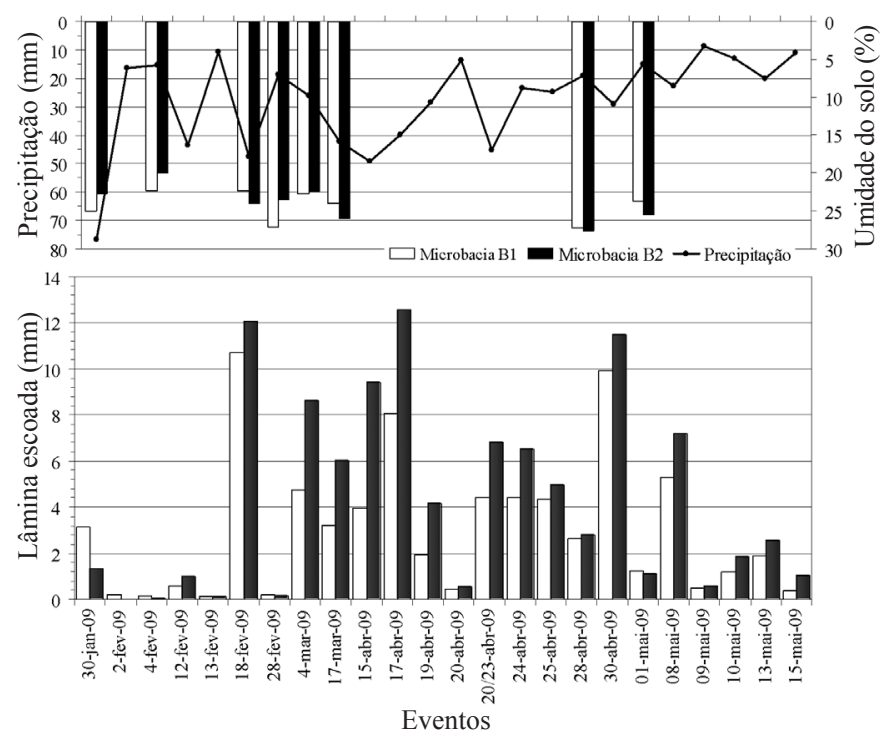

Figura 3. Precipitação, lâmina escoada e umidade do solo no ano hidrológico de 2009 nas microbacias B1 (raleada) e B2 (preservada)

desmatadas em Sumé, PB, e apontaram a importância da vegetação rasteira remanescente e o crescimento posterior da mesma sobre modificações no padrão das respostas hidrológicas.

A partir do dia 18-fev-09 observou-se que a lâmina escoada em B2 foi, em média, $46 \%$ superior à escoada em B1. Uma vez que as bacias possuem o mesmo tipo de solo e estavam sujeitas a eventos de precipitação de mesmo padrão (altura, intensidade e duração) atribui-se a diferença no deflúvio de B1 à recuperação da vegetação herbácea pós-tratamento; Iromé et al. (2006) também destacam a importância do restabelecimento da vegetação removida como fator de destaque na modificação do escoamento superficial.

Foram analisados as precipitações e os hidrogramas registrados nos dias 30-jan-09 (Figura 4) e 18-02-09 (Figura 5) nas microbacias $\mathrm{B} 1$ e $\mathrm{B} 2$, respectivamente; o hidrograma de B1 dia 30-jan-09 reflete o efeito do raleamento, no qual se verificou o maior pico de descarga; já os hidrogramas do dia 18-fev-09 apresentaram o maior pico de descarga registrado em 2009 (evento extremo deste ano); a forma desses hidrogramas é praticamente idêntica, tal como a resposta à intensidade das precipitações nas duas microbacias (Figuras 4 e 5).

Observa-se, no evento do dia 30-jan-09, a necessidade de uma precipitação acumulada de aproximadamente $24 \mathrm{~mm}$ para iniciar o escoamento (Figura 4) com tempo de início similar nas duas microbacias o que se deve à similaridade entre seus tempos de concentração (Tabela 1).

No hidrograma da Figura 4 observam-se dois picos; imediatamente após o primeiro pico inicia-se a curva de depressão da vazão mas a umidade antecedente do solo, associada a uma precipitação de intensidade de aproximadamente $10 \mathrm{~mm}$ $\mathrm{h}^{-1}$ produziu uma elevação na vazão, até atingir o segundo pico.

Entre as duas microbacias observa-se, em B1 (Figura 4) as maiores vazões específicas reforçando a hipótese da pesquisa de que o raleamento aplicado modifica a resposta hidrológica neste caso, os picos de descarga.

A diferença na descarga máxima entre as duas microbacias para este evento foi de $132 \%$, contudo e apesar desta
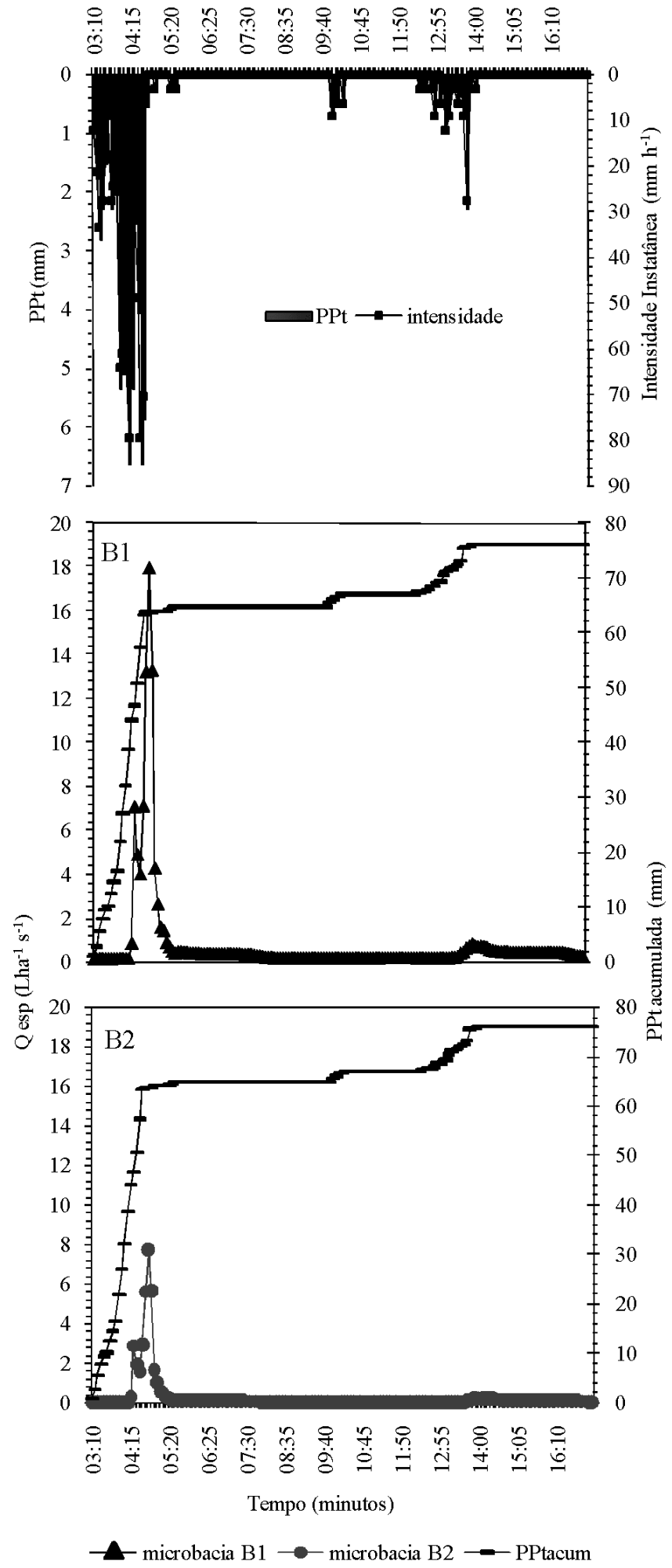

Figura 4. Precipitações (PPt) e hidrogramas das microbacias B1 e B2 para o evento do dia 30-jan-09. Qesp representa a vazão específica

verificação, o efeito do raleamento na vegetação de Caatinga em resposta às modificações do padrão hidrológico, não se mostrou totalmente conclusivo mesmo com a forte evidência do incremento da vazão específica pela intervenção antrópica. Embora tenha sido constatada elevação nas descargas máximas em B1, as lâminas escoadas foram, em 


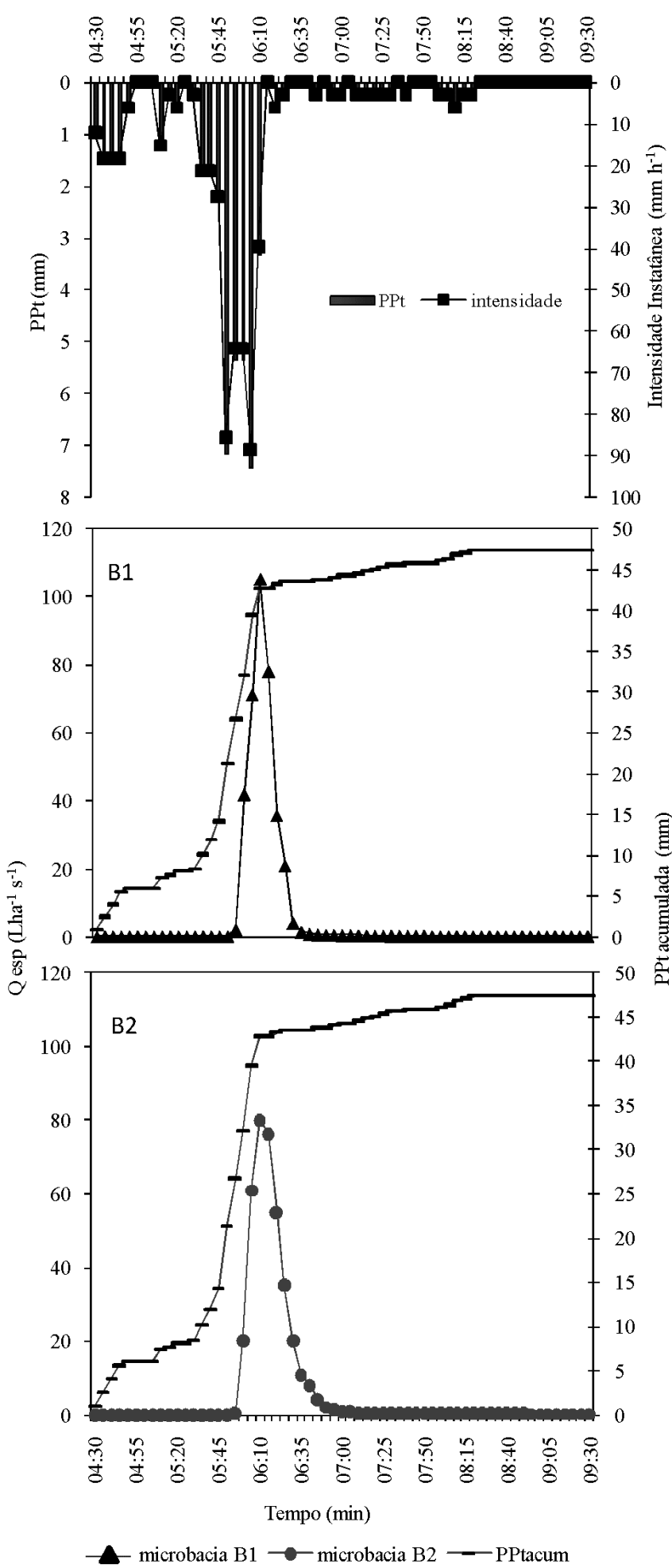

Figura 5. Precipitações (PPt) e hidrogramas das microbacias B1 e B2 para o evento do dia 18-fev; o maior registrado em 2009. Qesp representa a vazão específica

média, superiores em B2, conforme discutido antes (Figura 3); desta forma, o crescimento da vegetação herbácea após o tratamento e a manutenção dos restos vegetais sobre o solo após o raleamento, exerceu influência na redução do escoamento em B1; contudo, tornam-se imprescindíveis observações mais sequencia de investigações sobre qual cobertura vegetal promove maior redução do escoamento sobre a área: a herbácea ou a arbórea.

Na Figura 5 observa-se o hidrograma do maior evento registrado em 2009; da mesma forma que no evento anteriormente analisado verificou-se, também, maior descarga específica na unidade experimental B1. A hipótese de que os parâmetros morfométricos pudessem influenciar de forma expressiva a elevação das descargas máximas específicas foi descartada, uma vez que as microbacias são morfometricamente similares apresentando declividades de 8,7 e $10,6 \%$ e tempo de concentração de 0,57 e 0,68 h em B1 e B2, respectivamente (Tabela 1); admite-se, portanto, que a remoção parcial da vegetação tenha contribuído para o incremento dos picos de vazão em B1, corroborando com os resultados de Bartley et al. (2006) que também investigaram a influência da cobertura vegetal sobre processos hidrológicos em microbacias de clima semiárido, na Austrália.

A amplitude entre os picos de descarga máxima das duas bacias para o evento em análise atingiu o patamar de $60 \%$; no entanto, mesmo se tratando de um evento extremo para este ano, tal amplitude não superou a diferença atingida no início do tratamento (Figura 4) período em que a microbacia B1 ainda não estava totalmente coberta pela vegetação herbácea. Mesmo que tenham sido constatadas maiores lâminas escoadas em B2, os resultados identificam que o raleamento contribuiu para a elevação das vazões máximas.

A cobertura vegetal é considerada fator importante na definição do padrão de movimento da água em uma bacia (Garcia-Ruiz et al., 2008); assim, a remoção parcial ou total altera o comportamento hidrológico influenciando na disponibilidade hídrica. O surgimento da vegetação herbácea com o raleamento e maior penetração de luz, tal como a conservação dos resíduos vegetais sobre o solo favoreceram a infiltração, contribuindo para manutenção de água no sistema e reduzindo o escoamento superficial (Kang et al., 2001). Logo, devido ao poder de resiliência constatado pelo rápido crescimento da vegetação herbácea em B1, com maiores lâminas escoadas somente nos eventos iniciais, os resultados sugerem ter havido alterações no deflúvio como consequência do raleamento.

A Figura 6 mostra a correlação linear entre as vazões específicas máximas e as lâminas escoadas por evento nas duas microbacias, com coeficiente de determinação de $90 \%$ de ajuste para a microbacia B2 e $88 \%$ para a B1, ambas com indicação de forte correlação (Milton, 1992).

Embora se tenha verificado que, em média, as lâminas escoadas foram maiores em B2 (Figura 3) o mesmo não pode ser dito para as vazões máximas. De acordo com as equações de correlação da Figura 6 observa-se, em B2, um incremento de $5,1 \mathrm{~L} \mathrm{ha}^{-1} \mathrm{~s}^{-1}$ nas vazões específicas máximas para cada milímetro de lâmina escoada por evento e em B1, cuja vegetação foi parcialmente removida, um incremento de $7,9 \mathrm{~L} \mathrm{ha}^{-1} \mathrm{~s}^{-1}$. Esses resultados confirmam os encontrados por Iroumé et al. (2006) ao verificarem efeito da remoção da vegetação no incremento de descargas em microbacias no Chile. Constatase, para lâminas superiores a $6 \mathrm{~mm}$, uma tendência de picos de descarga superiores na unidade experimental B1 cuja vegetação foi parcialmente removida. 


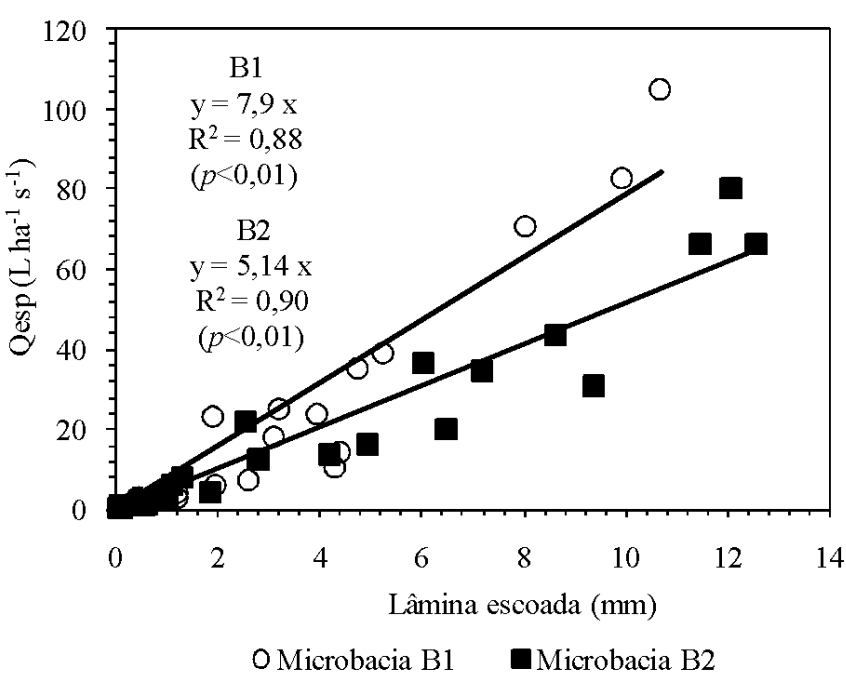

Figura 6. Vazões específicas máximas (Qesp) versus lâminas escoadas para os eventos do ano de 2009

Torna-se importante relatar que, apesar dos resultados preliminares, faz-se necessário um sequenciamento maior de observações, sobremaneira quanto aos eventos de maior magnitude, que não ocorreram para o ano em avaliação.

As correlações lineares das vazões máximas específicas $\left(\mathrm{Q}_{\text {esp }}\right)$ com as precipitações acumuladas anteriores até os picos $\left(\mathrm{PPT}_{\text {ant }}\right)$ e com as intensidades máximas em $30 \mathrm{~min}\left(\mathrm{I}_{30}\right)$ para o ano de 2009, estão na Figura 7A e B, respectivamente; referidas correlações foram empregadas para se avaliar individualmente a interferência das variáveis intensidade $\left(\mathrm{I}_{30}\right)$ e acúmulo de água no solo, sobre a elevação das descargas máximas e, assim, verificar o efeito de outras variáveis, além da cobertura vegetal, sobre as respostas hidrológicas.

O modelo de correlação linear entre as vazões máximas específicas e as precipitações acumuladas anteriores aos picos nas microbacias B1 e B2 (Figura 7A) foi explicado, respectivamente, com 79 e $78 \%$ de ajuste $(p<0,01)$ indicando correlação individual moderada (Milton, 1992). Esta correlação sugere que as precipitações acumuladas anteriores são importantes na explicação do efeito do acúmulo de água no solo sobre a elevação das vazões máximas específicas enquanto a Figura 7B indica que o modelo de correlação linear entre as vazões máximas específicas e as intensidades máximas em 30 min nas microbacias B1 e B2, foi explicado respectivamente com 83 e $73 \%$ de ajuste $(P<0,01)$ sugerindo correlação individual de moderada a forte.

De acordo com a Figura 7A, a produção de deflúvio nas microbacias B1 e B2 ocorre para precipitações superiores a 8 e $6 \mathrm{~mm}$, respectivamente; dependendo da umidade antecedente do solo, a Figura 7B mostra que a produção de deflúvio nas microbacias B1 e B2 ocorre para intensidades máximas de chuvas superiores a 15,7 e $12,6 \mathrm{~mm} \mathrm{~h}^{-1}$, respectivamente, com taxa de acréscimo de vazão de, respectivamente, 1,9 e 1,4 L ha $^{-1} \mathrm{~s}^{-1}$ por cada $\mathrm{mm} \mathrm{h}^{-1}$ registrado.

A análise acima reforça a premissa do envolvimento de outros atributos, além da cobertura vegetal, em explicar as variações de vazão sugerindo tratar-se de um processo multivariado. De fato, o processo chuva-deflúvio é bastante complexo e correlações simples entre poucos atributos muitas vezes não fornecem

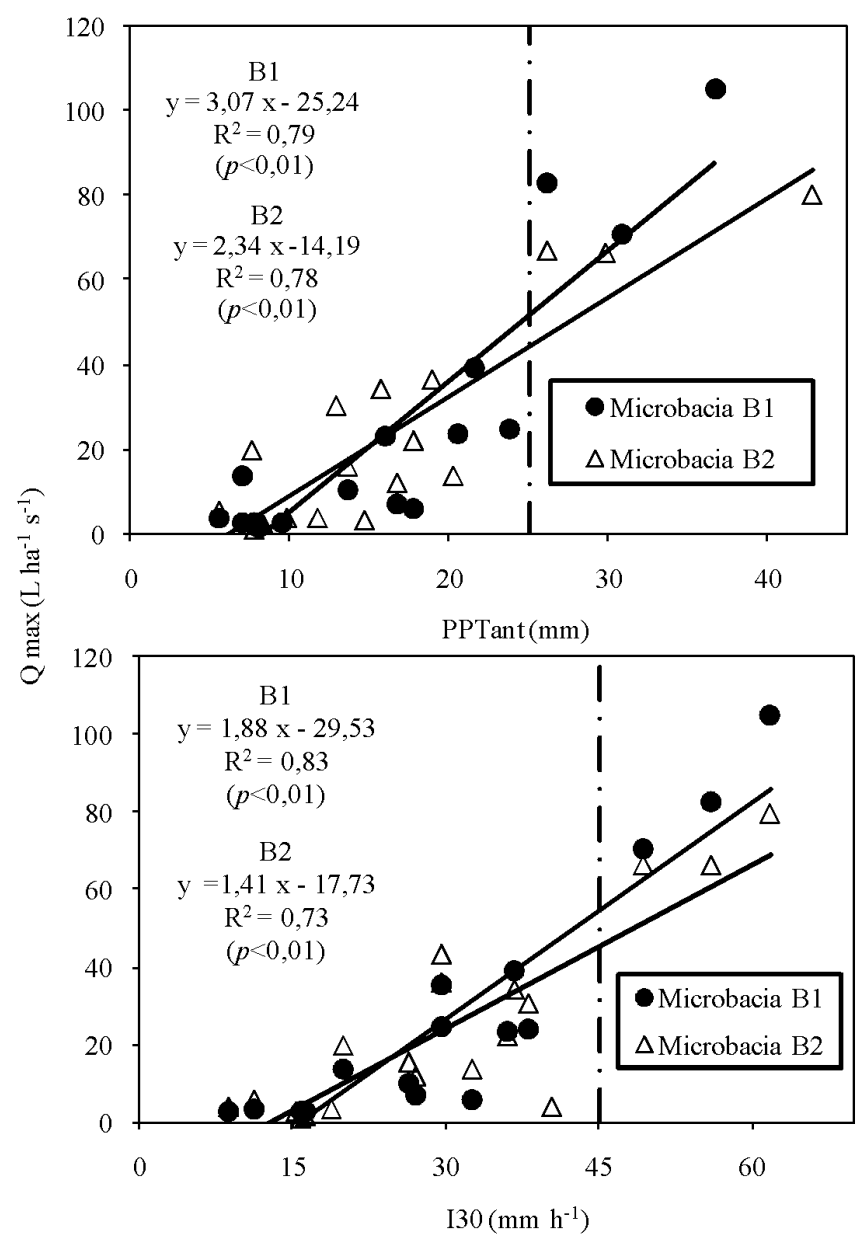

Figura 7. Vazões máximas específicas $\left(\mathrm{Q}_{\text {eso }}\right)$ versus precipitações acumuladas ininterruptamente até os picos $\left(\mathrm{PPT}_{\text {ant }}\right)(\mathrm{A})$ e intensidades máximas em $30 \mathrm{~min}$ $\left(\mathrm{I}_{30}\right)(\mathrm{B})$ para o ano de 2009

resultados satisfatórios. Entretanto, essas análises são de grande importância para indicações de tendências e entendimento quali-quantitativo desses processos (Srinivasan et al., 2003). Contudo se observa, nas duas unidades experimentais, que a análise individualizada dos atributos hidrológicos, precipitação acumulada anterior ao pico (Figura 7A) e intensidade máxima em 30 min (Figura 7B) se correlacionou com a vazão máxima a nível de $1 \%$ de probabilidade; tais resultados apontam a expressiva influência dessas variáveis sobre as respostas hidrológicas nas microbacias avaliadas. Alencar et al. (2006) discutem, estudando microbacias no Distrito Federal, sobre a complexidade de se encontrar correlações significativas entre diferentes variáveis hidrológicas mesmo pelo emprego de regressão múltipla.

A correlação entre intensidade máxima em 30 min e vazão específica máxima ocorre devido, sobremaneira, às características do clima da região formado por chuvas convectivas de curta duração e alta intensidade (Rodrigues et al., 2008) favoráveis à elevação das vazões máximas. Por outro lado, as precipitações acumuladas ininterruptamente até o pico, contribuem para elevação da umidade do solo proporcionando uma condição em que pequenas lâminas precipitadas sobre a área são suficientes para promover a elevação do deflúvio. 


\section{Conclusões}

1. Observaram-se alterações no escoamento superficial como consequência da retirada parcial da vegetação por raleamento; entretanto, as modificações no padrão de escoamento médio foram maiores nos eventos iniciais pós-raleamento enquanto nos demais eventos a lâmina escoada média foi superior na microbacia preservada.

2. O manejo aplicado favoreceu o crescimento da vegetação herbácea influenciando na retenção de água e aumentando a oportunidade de infiltação promovendo, assim, redução no escoamento superficial na microbacia raleada.

3. Verificou-se que as descargas específicas máximas na microbacia raleada superaram as da microbacia preservada.

\section{Agradecimentos}

Os autores agradecem ao Conselho Nacional de Desenvolvimento Científico e Tecnológico (CNPq) pelo apoio através da concessão de bolsas aos pesquisadores deste trabalho.

\section{Literatura Citada}

Aguiar, M. I.; Maia, S. M. F.; Oliveira, T. S.; Mendonça, E. S.; Araújo Filho, J. A. Perdas de solo, água e nutrientes em sistemas agroflorestais no município de Sobral, CE. Revista Ciência Agronômica, v.37, p.270-278, 2006.

Alencar, D. B. S.; Silva, C. L.; Oliveira, C. A. Influência da precipitação no escoamento superficial em uma microbacia hidrográfica do Distrito Federal. Engenharia Agrícola, v.26, p.103-112, 2006.

Alves, N. N. L. Caracterização de micro-bacia hidrográfica experimental no semi-árido brasileiro como suporte a estudos da degradação. Fortaleza: UFC, 2008.77p. Dissertação Mestrado

Andrade, E. M.; Araújo, L. F. P.; Rosa, M. F.; Disney, W.; Alves, A. B. Seleção dos indicadores da qualidade das águas superficiais pelo emprego da análise multivariada. Engenharia Agrícola,v.27, p.683-690, 2007.

Araújo, J. C.; Guntner, A.; Bronstet, A. Loss of reservoir volume by sediment deposition and its impact on water availability in semiarid Brazil. Hydrological Sciences Journal, v.51, p.157-170, 2006.

Bartley, R.; Roth, C. H.; Ludwig, J.; Macjannet, D.; Liedloff, A.; Corfield, J.; Hawdon, A.; Abbott, B. Runoff and erosion from Australian's tropical semi-arid rangelands: Influence of ground cover for differing space and time scale. Hydrological Processes, v.20, p.3317-3333, 2006.

Brito, L. T. L.; Cavalcanti, N. B.; Anjos, J. B. ; Silva, A. S.; Pereira, L.A.Perdas de solo e de água em diferentes sistemas de captação in situ no semi-árido brasileiro. Engenharia Agrícola, v.28, p.507-515 2008.
FUNCEME - Fundação Cearense de Meteorologia. Séries pluviométricas do posto Iguatu - Ce (1974-2008). <http:// www.funceme.br/>. 30 Jan. 2009.

Gaiser, T.; Krol, M.; Frischkorn, H.; Araújo, J. C. Global change and regional impacts. Berlin: Springer Verlag, 2003. 428p.

Garcia-Ruiz, J. M.; Regués, D.; Alvera, B.; Lana-Renault, N.; Serrano-Muela, P.; Nadl-Romero, E.; Navas, A.; Latron, J.; Martí-Bono, C. Arnáez, J. Flood generation and sediment transport in experimental catchments affected by land use changes in the central Pyrenees. Journal of Hydrology, v.274, p.30-46, 2008.

Iroumé, A.; Mayen, O.; Huber, A. Runoff and sediment peak flow responses to timber harvest and forest age in southern Chile. Hydrological Processes,v.20, p.37-50, 2006.

Kang, S.; Zhang, L.; Song, X.; Zhang, S.; Liu, X.; Liang, Y.; Zheng.; S. Runoff and sediment loss responses to rainfall and land use in two agricultural catchments on the Loess Plateau China. Hydrological Processes, v.15, p.977-988, 2001.

Mamede, J. L. Reservoir sedimentation in dryland catchments: Modelling and management. Potsdam: Uni/Potsdam, 2008. 120p. Tese Doutorado

Medeiros, P. H. A.; Guntner, A.; Francke, T.; Mamede, J. L.; Araújo, J. C.Modellingspatio-temporal patterns of sediment yield and connectivity in a semi-arid catchment with the WASA-SED model. Hydrological Sciences Journal, v.55, p.636-648, 2010.

Mello, C. R.; Lima, J. M.; Silva, A. M. Simulação do deflúvio e vazão de pico em microbacia hidrográfica com escoamento efêmero. Revista Brasileira de Engenharia Agrícola e Ambiental, v.11, p.410-419, 2007.

Milton, J. S. Statistical methods in the biological and health sciences. 2.ed. New York: McGrow-Hill, 1992. 526p.

Rodrigues, J. O .; Andrade, E. M.; Oliveira, T. S.; Lobato, F. A. Equações de intensidade-duração-frequência de chuvas para as localidades de Fortaleza e Pentecoste, Ceará. Scientia Agrária, v.9, p.511-519, 2008.

Santos, E. H. M.; Griebeler, N. P.; Oliveira, L. F. C. Relação entre uso do solo e comportamento hidrológico na Bacia Hidrográfica do Ribeirão João Leite. Revista Brasileira de Engenharia Agrícola e Ambiental, v.14, p.826-834, 2010.

Srinivasan, V. S.; Santos, C. A. G.; Galvão, C. O. Erosão hídrica do solo brasileiro: A experiência da Bacia Experimental de Sumé. Revista Brasileira de Recursos Hídricos, v.8, p.5773, 2003.

Thomaz, E. L. The influence of traditional steep land agricultural practices on runoff and soil loss. Agricultural, Ecosystem and Environment, v.130, p.23-30, 2009.

Tucci, C. E. M. Escoamento superficial. In: Tucci, C. E. M. (org.) Hidrologia: Ciência e aplicação.4.ed. Porto Alegre: ABRH/UFRGS, 2007. Cap.11, p.391-441. 